\title{
(In) Vestindo Histórias: fragmentos do processo de patrimonialização do Acervo de Indumentária do Movimento Tradicionalista Gaúcho de Porto Alegre - RS
}

Dressing up (in) stories: fragments from the patrimonialisation process of the clothing collection from the Traditionalist Gaucho Movement (Movimento Tradicionalista Gaúcho, MTG) in Porto Alegre - RS

\section{Caroline Muller}

\section{Ronaldo de Oliveira Corrêa}

Pós Doutorado no Programa de Pós Graduação em Antropologia Social - UFRGS rcorrea@ufpr.br 
(In) Vestindo Histórias: fragmentos do processo de patrimonialização do Acervo de Indumentária do Movimento Tradicionalista Gaúcho de Porto Alegre - RS

\author{
Dressing up (in) stories: fragments from the patrimonialisation process of the clothing \\ collection from the Traditionalist Gaucho Movement (Movimento Tradicionalista \\ Gaúcho, MTG) in Porto Alegre - RS
}

Caroline Muller e Ronaldo de Oliveira Corrêa

\section{Resumo}

Este texto apresenta histórias sobre o processo de patrimonialização do Acervo de Indumentária do Movimento Tradicionalista Gaúcho (MTG), localizado na cidade de Porto Alegre, Rio Grande do Sul. O acervo é descrito pelos(as) interlocutores(as), que narram as suas experiências cotidianas enquanto participantes do processo. Este conjunto de informações tece uma forma de contar histórias, cuja intenção não é reconstruí-las de um modo linear e cronológico, mas sim plural, múltiplo e fragmentado. Ainda, a pesquisa apoiou-se nas fontes escritas, tais como documentos, registros fotográficos e diários de campo acessados durante a pesquisa empírica realizada nos anos de 2014 e 2015. Ao destacar as memórias, os saberes e as trajetórias dos(as) interlocutores(as) no acervo, foi possível compreender que a indumentária os constitui e escancara seus ideais e vontades.

Palavras- chave: Acervo, indumentária, memória.

\begin{abstract}
This text presents stories about the patrimonialisation process of the clothing collection from the Traditionalist Gaucho Movement (Movimento Tradicionalista Gaúcho, MTG), located in the city of Porto Alegre, Rio Grande do Sul. The collection is described by the interlocutors who narrate their daily experiences as participants in the process. This set of information weaves a form of storytelling, whose intention is not to rebuild the narratives in a linear and chronological way, but in a way that is plural, multiple and fragmented. Still, the research is based on written sources, such as documents, photographic records and field Journals accessed during the empirical research conducted in the years 2014 and 2015. By highlighting the memories, the knowledge and the trajectories from the interlocutors at the collection, it was possible to understand that the clothing is a part of who they are and it sets out to open their ideals and wills.
\end{abstract}

Keywords: Collection, clothing, memory 


\section{Introdução}

Este estudo trata das relações entre patrimônio, memória, indumentária gaúcha e sujeitos. Por acreditar que hábitos culturais envolvem o emprego de artefatos e que os artefatos estão relacionados com as práticas sociais, maneiras de pensar e formas de comportamento (MILLER, 2013; SANTOS, 2005), o presente trabalho traz como pauta fragmentos sobre o processo de patrimonialização do Acervo de Indumentária, idealizado pelo Movimento Tradicionalista Gaúcho (MTG), localizado na cidade de Porto Alegre - RS. O MTG é uma entidade sem fins lucrativos que "dedica-se à preservação, resgate e desenvolvimento da cultura gaúcha, por entender que o tradicionalismo é um organismo social de natureza nativista, cívica, cultural, literária, artística e folclórica" (MTG, 2015). O movimento tem como objetivo orientar as atividades dos seus filiados e entidades associativas, conhecidas por Centro de Tradições Gaúchas - CTGs, sendo constituído desde 1966. Diversas atividades são realizadas ao longo do ano, onde buscam através da história do estado reinventar hábitos e costumes do passado.

O Acervo de Indumentária do movimento é um espaço que desde 2003 está dedicado a guardar os trajes que caracterizam essa história, estando relacionados com os valores e crenças das pessoas que os utilizam. Nele estão contidas diferentes peças, memórias, modos de fazer e viver. Seu surgimento é marcado para atender o Desfile Temático, que ocorre uma vez por ano na cidade de Porto Alegre. O Desfile Temático é uma das atividades organizadas pelo MTG e tem como objetivo realçar os motivos tradicionais do Rio Grande do Sul e a cultura do estado.

Neste sentido, partimos das memórias dos(as) interlocutores(as) e de algumas das práticas e costumes circunscritos ao MTG para discutir a respeito do Acervo de Indumentária do movimento. Tais memórias foram acessadas por meio de entrevistas ${ }^{1}$ realizadas em acordo com os princípios da História Oral, em Porto Alegre, nos anos de 2014 e 2015. Os narradores foram encarados como protagonistas desta trajetória. Esta exibição tem como finalidade trazer essas pessoas para perto, destacando suas memórias, saberes e experiências.

\footnotetext{
${ }^{1}$ Todas as entrevistas são citações diretas e transcrições literais que foram utilizadas como recurso para o uso de dados. Para sistematizar e organizar as informações obtidas a partir das entrevistas foi desenvolvido um protocolo de transcrição, com base nos protocolos elaborados por Corrêa (2008) e Tessari (2014). Os(as) interessados(as) podem solicitar a versão integral aos autores deste artigo.
} 
A roupa é compreendida como patrimônio, carregada de ideias e valores da sociedade que a consumiu e usou. Segundo Benarush (2012) todo objeto pertencente a uma coleção, seja privada ou pública, está lá por decisão de alguém. Coleciona-se por algum motivo, sendo essa pesquisa um esforço que busca entender a dinâmica entre a indumentária gaúcha, os sujeitos e o patrimônio idealizado pelo MTG.

Halbwachs (1990) e Nora (1993) nos ajudam a elucidar questões que transpassam as Teorias da Memória ao defenderem que nossas lembranças são coletivas e que as pessoas que passam por nossas vidas contribuem com o nosso rememorar. Para Halbwachs, a memória individual existe a partir da memória coletiva, ao passo que "cada memória individual é um ponto de vista sobre a memória coletiva" (HALBWACHS, 1990, p. 51). E esses olhares mudam conforme o lugar que os sujeitos ocupam e as relações mantidas com outros grupos.

\section{Procedimentos metodológicos}

No que diz respeito ao método adotado para a realização desta pesquisa, ela caracteriza-se como um estudo exploratório, que tem "como objetivo proporcionar maior familiaridade com o tema" (GIL, 2002, p. 41). A trajetória de investigação teve início no levantamento bibliográfico e foi conduzida para a pesquisa empírica, coleta de documentos e entrevistas com os(as) interlocutores(as). Ao buscarmos narrativas de sujeitos que participaram do processo de patrimonialização do Acervo de Indumentária, entendemos que esse processo foi reconstruído coletivamente, onde cada interlocutor(a) compartilhou suas experiências, olhares e cenários. De acordo com esse pressuposto, destacam-se como principais interlocutores(as) da pesquisa: Manoelito Carlos Savaris, Josemar Basso, Ana Beatriz Souza Debom, Gustavo Bierhals, Odila Paese Savaris e Ana Marta Vasconcelos Pochmann.

As entrevistas têm por propósito compreender as percepções e experiências individuais, permitindo entender que os modos de lembrar variam de acordo com a trajetória de cada sujeito. O narrador cumpre um importante papel, pois é baseado em sua vida e experiências que são reconstruídas e materializadas as histórias do Acervo de Indumentária. Também é relevante mencionar que o dom do narrador "é poder contar sua vida, sua dignidade é contá-la inteira” (BENJAMIN, 1994, p. 221). Mais do que uma informação, o narrador expõe sua vida e nos convida a novas experiências e a 
novas formas de entender o mundo. Este registro, de acordo com Bosi (1994), alcança uma memória pessoal como também social, familiar e grupal.

As negociações com estes narradores sobre data, local e assunto foram constantes ao longo do estudo, sendo apoiadas ao método da História Oral. A História Oral, como postura metodológica, declara que uma história pode ser escrita a partir da fala de seus(uas) protagonistas. Logo, os fatos narrados e memorados são informações obtidas tendo com base um roteiro de entrevista semiestruturado. As entrevistas foram gravadas em áudio e transcritas na íntegra, sendo que todas foram lidas e aprovadas pelos(as) entrevistados(as). Também utilizamos como registro e análise os diários de campo, a ficha dos(as) interlocutores(as), registro e protocolo de imagens.

Por via da organização em turnos, as transcrições contribuíram para reconstruirmos as narrativas coletadas e interpretar os sentidos contidos nestas narrativas. Indicações derivadas de Corrêa, Rial e Queluz (2012) e Benjamin (1994) foram utilizadas ao refletirmos sobre a narrativa como experiência, em que os relatos são narrados de acordo com os desejos e com a reflexão de cada sujeito.

Somando às entrevistas, completamos a análise com os documentos localizados ao longo da pesquisa empírica, explicitando os sentidos e significados contidos nos discursos sobre o Acervo de Indumentária. Buscamos acompanhar as transformações ocorridas nos tempos, observando as formas de organização dos espaços ocupados, as indumentárias que compuseram os cenários e como este coletivo compreende e constrói um patrimônio. Passemos então às narrativas dos(as) interlocutores(as).

\section{Quando um patrimônio conta histórias}

Uma das formas de pensar a história de algum evento é ter como referência datas e lembranças compartilhadas entre os sujeitos participantes desta trajetória. No entanto, Pollak (1992, p. 209) provoca tal método e nos convida a trabalhar com escritas biográficas ou com relatos, e argumenta que a história está se transformando em histórias, histórias parciais e plurais. A cronologia, para o autor, é plural e deve ser considerada em função do seu modo de construção. Esta é uma perspectiva que entendemos como adequada para ser pensada no contexto do acervo estudado, ao passo que as peças ali compostas são possíveis de serem guardadas muito em razão dos diferentes saberes e ações dos(as) interlocutores(as) desta pesquisa. 
Neste compasso, no Acervo de Indumentária a proximidade entre as pessoas se deve aos artefatos nele contidos. O acervo tomou forma no momento em que as indumentárias e os acessórios foram definidos como tema que reuniria pessoas do setor administrativo do MTG, empresas parceiras, colaboradores(as), coordenadores(as), costureiras, entre outros. Todos(as), cada um(a) de sua maneira, tiveram ou ainda têm vivências e experiências com o acervo. Manoelito Carlos Savaris, atual presidente do movimento e no ano em que surgiu o acervo, comenta em depoimento que a ideia surgiu por intermédio do Desfile Temático de Porto Alegre:

Em 2003 nós realizamos o primeiro Desfile Temático de Porto Alegre e o tema na época foi "Soldado Farroupilha: o herói anônimo" e para fazer o desfile (...) a gente necessitou confeccionar roupas masculinas e femininas, derivadas de pesquisa histórica. Feito as indumentárias, isso constituiu um primeiro lote que a Fundação Cultural Gaúcha do MTG ficou encarregada de guardar, porque ela é a realizadora do evento. (Manoelito Carlos Savaris, entrevista, dezembro de 2014).

Criado em 2003, o acervo surgiu em um dos seus mandatos como presidente do MTG, a partir da consolidação do $1^{\circ}$ Desfile Temático na cidade Porto Alegre. Realizado anualmente, o desfile é um dos eventos tradicionais da cidade que ocorre na Semana Farroupilha e é promovido pela Fundação Cultural Gaúcha do MTG. O interlocutor inicia sua fala apontando que o acervo emergiu como estratégia para acondicionar indumentárias criadas exclusivamente para o Desfile Temático. A fundação, que tem como responsabilidade o planejamento e a realização dos eventos, teve também o papel de organizar e localizar um lugar para as indumentárias.

Quanto ao suporte financeiro, Savaris assegura que "feito o primeiro (...) a primeira indumentária (...) isso foi pago com dinheiro público, porque isso fez parte da Lei Rouanet. Nós aprovamos o projeto na Lei Rouanet e compramos tecidos, mandamos fazer" (Manoelito Carlos Savaris, entrevista, dezembro de 2014). Já Josemar Basso, responsável pela organização do $1^{\circ}$ Desfile Temático e pela criação do Acervo de Indumentária, declara que as peças não foram produzidas no primeiro ano de surgimento do acervo, conforme apresenta o fragmento ${ }^{2}$ a seguir:

Basso: Nós mandamos fazer todos os (...) o desenho de todos os trajes. Foi o primeiro e único ano que a gente conseguiu fazer isso. Por que o que acontecia? Muitas coisas como a bota e a bombacha os caras tinham, então

\footnotetext{
${ }^{2} \mathrm{O}$ uso de fragmentos é fundamental para o entendimento das questões abordadas no texto e, por esse motivo, não há uma reconstrução do parágrafo, mas sim uma transcrição na íntegra.
} 
não precisava ter. Isso aqui o cara também tem e a gente foi fazendo né, de acordo com o tipo de vestimenta. Então esse ano tu pode ver que tinha tudo (...) e o Acri ele fez toda a produção.

Entrevistadora: Como é o nome dele?

Basso: Acri, se eu não me engano é Edison Acri. Depois eu vejo isso.

Entrevistadora: E isso foi no primeiro ano? Lá em 2003?

Basso: Não não não, isso foi depois. (Josemar Basso, entrevista, maio de 2015).

Para Savaris, as primeiras indumentárias foram criadas em 2003 e para Basso, não, tanto que ele comenta que "em 2003 nós aproveitamos muita coisa que as pessoas tinham já, que os CTGs tinham” (Josemar Basso, entrevista, maio de 2015). O compasso do tempo para Basso e Savaris é diferente, ele não corre com a mesma exatidão. Portanto, quando analisamos as narrativas dos sujeitos não temos a pretensão de saber qual data condiz com a realidade histórica. Savaris anuncia que o momento inaugural do acervo está atrelado à confecção das peças, ao passo que para Basso se dá com o uso de vestimentas dos participantes dos CTGs.

Os desenhos (Figura 1) destas peças foram produzidos por Edison Acri, autor citado no Art. $3^{\circ}$ referente às Diretrizes para os trajes de época do $\mathrm{MTG}^{3}$. Savaris esclarece que os desenhos realizados por Acri seguem pesquisas históricas baseadas em autores que o MTG reconhece como conhecedores da história do estado.

\footnotetext{
${ }^{3}$ Toda e qualquer atividade ligada ao MTG que exige o uso da indumentária gaúcha deve seguir as normas estabelecidas neste documento. Disponível em: <http://13regiaotradicionalista.com.br/wpcontent/uploads/2014/09/2_1_DIRETRIZ_EPOCA.pdf>. Acesso em: 22 set. 2015.
} 
Figura 1 - Desenhos de Edison Acri sem data.

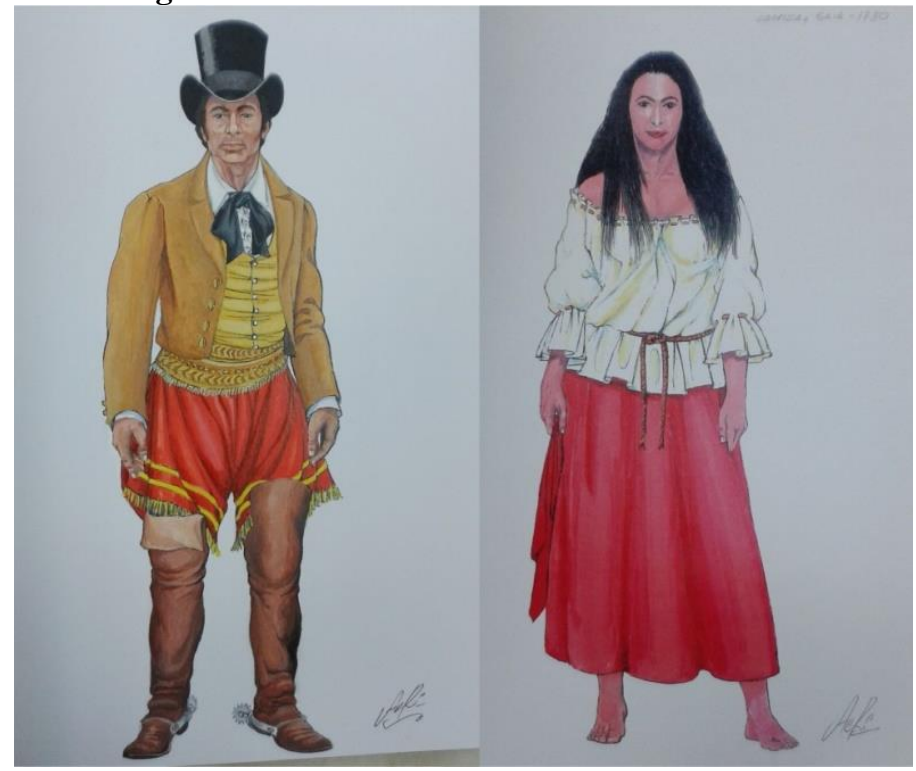

Fonte: A autora (25.05.2015).

Além de Acri, outro autor se destaca nos documentos encontrados ao longo da pesquisa empírica. Na Figura 2 constam ilustrações que foram localizadas na casa de Basso e denunciam que a quantidade, o tamanho e o modelo das peças não eram determinados somente pelos desenhos de Acri, mas também pelas ilustrações contidas no livro "Indumentária Sul-Riograndense no Decênio Farroupilha" (2008) de Luiz Carlos Gomes Hyarup.

Figura 2 - Registro do processo de produção das indumentárias baseado nas ilustrações de Hyarup.


Fonte: A autora (25.05.2015). 
Já sobre a produção das indumentárias:

Mandamos confeccionar em dois lugares: uma parte das roupas foram feitas pelas Lojas Renner e uma parte de roupas foram feitas pelas costureiras do Morro da Cruz, de Porto Alegre (...) que é uma associação de costureiras do Morro da Cruz, que é uma região muito pobre de Porto Alegre e que eles têm uma espécie de associação de mulheres que costuram. Então uma parte foi feito (...) as roupas mais delicadas, mais chiques, mais (...) que exigiam um rigor maior foram feitas pelas Lojas Renner e a outra parte foi feita pelas costureiras do Morro da Cruz. 2003. (Manoelito Carlos Savaris, entrevista, dezembro de 2014).

Foi a Tevah, tá? A indústria Tevah. Nós pedimos para eles fazerem uma série de coisas que foram criadas especificamente para isso. Acho que não foi no primeiro ano de 2003. Eu acho que foi no segundo que se (...) Francamente eu não tô bem lembrado. Eu precisaria ver isso daí (...) Nós tivemos uma parceria com o Morro da Cruz. O Morro da Cruz é (...) é uma, não dá pra dizer que é uma favela, mas é (...) tem uma entidade lá que é uma associação de costureiras do Morro da Cruz que a gente fez uma parceria e elas fizeram também 100 a 150, eu não lembro quantas roupas. Elas confeccionaram saias. O Tevah foi mais as casacas, casacões, alguns tipos de calça, colete. Isso o Tevah fez. A outra parte que era saia, chiripas e isso aí foi o Morro da Cruz. A Tevah é mais especializada mais em confecção de casacos, ternos e tudo e economicamente (...) aí são dois pontos: um o fato de ajudar uma entidade, entende? Porque é uma associação do morro e a outra também (...) que valia a pena. Então nós compramos os tecidos, tá? A gente dava os desenhos e elas davam a metragem e aí a gente comprava. (Josemar Basso, entrevista, maio de 2015).

A distinção entre os trajes se dá a partir de quem produz. Tais questões pressionam as formas pelas quais os trajes eram produzidos e utilizados, e também pressionam a forma como o movimento pensa estes artefatos. Para Savaris e Basso, a decisão de quem os confecciona envolve habilidades técnicas desejáveis para cada tipo de traje. Logo, quem produz estes artefatos está colado à distinção dos trajes.

Emídio, Ayres e Nunes (2014) discutem a respeito da motivação que sustenta a decisão da terceirização da mão de obra nas pequenas empresas de confecção do vestuário no Brasil e mostram, a partir de um estudo de caso, que a terceirização seguiu um controle de qualidade que avaliava as peças com menor ou maior grau de operações. Nas Figuras 3 e 4 é possível observar brevemente que a peça confeccionada pela Associação do Morro da Cruz possui menos detalhes e costuras se compararmos com a desenvolvida pelas Lojas Tevah.

Ao selecionar as Lojas Tevah e/ou Renner para confeccionar as peças que "exigiam um rigor maior" e por ser "mais especializada mais em confecção de casacos, ternos", Savaris e Basso entendem que as empresas, por suas trajetórias e 
reconhecimento no mercado, possuem mais habilidades, recursos e técnicas do que as costureiras do Morro da Cruz. No tocante à Associação das Costureiras do Morro da Cruz, Basso declara que o movimento procurou colaborar com "uma associação do morro", o que os aproxima da ideia da política de assistência social ${ }^{4}$, que busca garantir o atendimento às necessidades básicas dos segmentos populacionais vulnerabilizados pela pobreza e pela exclusão social.

Figura 3 - Modelo produzido pelas costureiras do Morro da Cruz.


Fonte: A autora (15.07.2015).

\footnotetext{
${ }^{4}$ Constituição Federal de 1988, regulamentada pela Lei no 8.742 , de 07 de dezembro de 1993, intitulada Lei Orgânica da Assistência Social. Para maiores informações a respeito da política de Assistência Social no Brasil consultar:

<http://www.desenvolvimentosocial.pr.gov.br/arquivos/File/Capacitacao/material_apoio/mariaizabel_sua s.pdf>. Acesso em: 23 set. 2015.
} 
Figura 4 - Modelo produzido pela empresa Tevah.

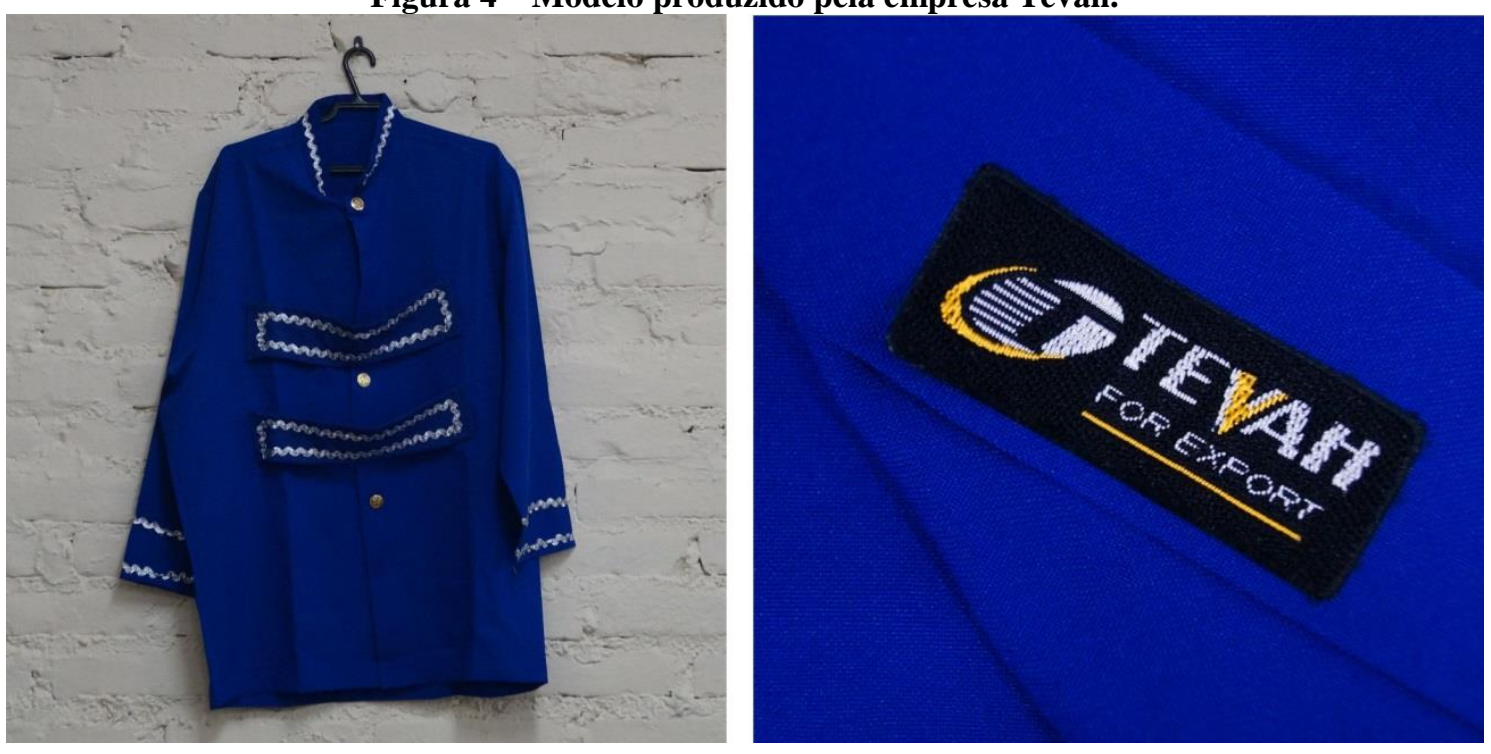

Fonte: A autora (15.07.2015).

Algumas indumentárias não precisaram ser confeccionadas, tais como as bombachas - calças masculinas fofas e pregueadas, feitas em tecido de brim liso ou $\mathrm{xadrez}-\mathrm{e}$ as botas, pois para os participantes do movimento as peças que eles utilizam no cotidiano não precisam estar em um acervo. A criação das peças está relacionada a trajes de um passado distante, não mais acessado nos dias atuais, e que remetem à memória coletiva. Savaris reitera que "tu não vai encontrar o vestido de prenda e a bombacha masculina, porque os trajes atuais não precisam virar acervo, as pessoas já têm em casa. No acervo deve conter roupas que as pessoas não têm em casa" (Manoelito Carlos Savaris, entrevista, dezembro de 2014). Sobre o vestido de prenda, traje comum utilizado pelas mulheres nas atividades organizadas pelo movimento, Pochmann, coordenadora do acervo desde 2014 até os dias de hoje, diz que "isso é uma coisa que todo mundo tem. Qual CTG não vai ter vestido de prenda? Só quando vem uma pessoa de fora, que não é, que não faz parte do CTG é que vai precisar" (Ana Marta Vasconcelos Pochmann, entrevista, maio de 2015). Isso reforça que para eles a ideia de acervo é o que não está vinculado ao uso cotidiano.

Tal perspectiva evidencia que o acervo ultrapassa a função de suprir a demanda do desfile. É um lugar de memória, sendo essa a maneira do movimento de legitimar o passado que se encontra ameaçado de destruição. Nora nos dá suporte ao declarar que "se habitássemos ainda nossa memória não teríamos necessidade de lhe consagrar 
lugares" (NORA, 1993, p. 8). Ele não seria um lugar de memória se até agora vivessem as lembranças às quais estão relacionados. Neste sentido, é plausível compreender porque não encontramos trajes atuais no Acervo de Indumentária.

Savaris aponta que as indumentárias seguem os temas do desfile ao falar que "as roupas são criadas conforme o tema do ano, então a gente busca representar através das roupas uma parte da história do estado" (Manoelito Carlos Savaris, entrevista, dezembro de 2014). Ou seja, eles procuram reconhecer por meio da materialização dos trajes o que é ser gaúcho, tradicionalista. Neste sentido, a roupa é um marcador da ideia de gaúcho que atravessa o movimento. Ela não é neutra, evoca ações, indica preferências e formas de pensar o mundo, pois assim como as pessoas fazem as coisas, "estamos interessados, e na mesma medida, em como as coisas fazem as pessoas" (MILLER, 2013, p. 66).

Os trajes do Acervo de Indumentária são marcados por prescrições de fabricação, materiais e usos. Quando perguntamos para Pochmann sobre os tipos de peças que encontramos no acervo, ela responde:

Entrevistadora: Sim, mas agora pensando nas roupas que tem aqui (...) tu poderia me dizer o que podemos encontrar, os tipos de roupa que tem?

Pochmann: Bom (...) tem bastante farda, tem chiripá saia, tem chiripá fralda (...) que são diferentes (...) tem roupas de índio, de índia, tem fraques, tem alguns vestidos de época, vestidos de prenda, bombacha é alguma coisa. Bombacha completa masculina não tem, vestido de prenda ainda se tem alguma coisa aqui. Tem roupa de freira, tem roupa de padre, tem roupa de enfermeiro, enfermeira e (...) roupa infantil também tem bastante. Bastante não, tem alguma coisa de infantil.

Entrevistadora: Tem infantil.

Pochmann: Tem infantil. Tem roupa de jornaleiro, mas daí é infantil, roupas pequenas. Tem muito traje de (...) feminino, que é a saia e a blusa. (Ana Marta Vasconcelos Pochmann, entrevista, dezembro de 2014).

Já Savaris pontua que:

As roupas que temos lá dá para dividir por partes: nós temos (...) roupas de época, chamado (...) que é do período Farroupilha. Período, é aquele período do, da primeira metade do século XIX, basicamente isso. Tu vai encontrar lá roupas especialmente masculinas (...) basicamente calças, camisas túnicas e esse chiripá, que é a calça (...) como se fosse a calça. Tu vai encontrar algumas roupas femininas também: saias, também da época e de mulher simples. Tu vai encontrar roupas de escravo, masculinas e femininas, vai encontrar roupas de militares, especialmente imperiais: calça, túnicas, barretinas, chapéus, né (...) tem também. Tu vai encontrar alguma coisa de roupas de crianças (...). Tu vai encontrar também algumas roupas de italianos e de alemães (...) Tu vai encontrar lá roupas do negro, roupas do alemão, do 
italiano (...) essas são as roupas que tu vai encontrar lá. (Manoelito Carlos Savaris, entrevista, maio de 2015).

Pochmann fala acerca dos tipos de peças de forma objetiva e classificatória. Sua narrativa nos faz circular pelo Acervo de Indumentária como se ela estivesse lendo o que está escrito nas etiquetas das caixas e nos cabides com capas de plástico. Já Savaris, com sua paixão pela história e facilidade em contextualizar o assunto, inicia sua fala apresentando os trajes com uma breve noção do período histórico que o MTG valoriza. Ele tem um interesse em disparar no passado a legitimidade do acervo. O mais curioso e contraditório é que não são roupas de época que o acervo tenta preservar, mas sim, uma atualização do passado no presente.

Cada tipo de peça encontrada no acervo tem um valor simbólico, diferentes sentidos e potencializadas formas de ser gaúcho. Para Savaris, por exemplo, "o que, digamos assim, tem um reconhecimento mais importante é o chiripá, o chiripá chamado Farroupilha. É que ele predominou por muito tempo na história (...) ele vai do início do século XIX até o final do século XIX" (Manoelito Carlos Savaris, entrevista, maio de 2015). O chiripá é um tipo de saia vestida pelos homens, sem costuras, preso à cintura. Já Debom, ex-colaboradora do acervo, entende que a roupa que mais caracteriza o gaúcho é a vinculada aos açorianos.

\footnotetext{
Porque eles chegaram primeiro, foram os primeiros que vieram pra cá né. $\mathrm{E}$ a gente tem, eu tenho descendência de açorianos porque eu sou de Mostarda, minha avó também tinha. Lá é uma cidade, uma vila em que tudo é açoriano. Tem muito açoriano lá. Então eu gosto dos açorianos. A vestimenta deles é bonita, é um lenço colorido como o de português, mas são açorianos. Tem uma saia curta, tamanco, tem uns que colocam o chapéu por cima do lenço. É muito bonita a roupa de açoriano. (Ana Beatriz Souza Debom, entrevista, maio de 2015).
}

A interlocutora faz alusão aos trajes dos açorianos, sua origem, como o traje que caracteriza o gaúcho. O que importa para ela são suas histórias e raízes. Sua constituição como gaúcha está atrelada a este tipo de vestimenta. Gustavo Bierhals, atual vicepresidente da Fundação Cultural Gaúcha e um dos responsáveis pela organização do acervo, já fala que "é a bombacha (...) e o lenço que são primordiais para tu identificares o gaúcho" (Gustavo Bierhals, entrevista, maio de 2015). Ele identifica o gaúcho com o traje que é utilizado pelos tradicionalistas do movimento, com sua vestimenta quase que diária, tanto que reafirma: "mas o que identifica bem mesmo e tem a característica do 
nosso movimento é a bombacha, a bombacha e o lenço. Já é daí identificado o indivíduo" (Gustavo Bierhals, entrevista, maio de 2015).

Por meio destas discussões os interlocutores nos revelam que o processo de construção do acervo foi à base de muitas mãos. Todos os sujeitos mencionados anteriormente foram os responsáveis por transformar os artefatos em documentos, visto que "ele só vira documento quando é guardado, colecionado, mantido por alguém que investe nele sentimento" (BENARUSH, 2012, p. 88). Esse processo de objetos materiais do cotidiano para um espaço de museus e patrimônios envolve um processo de colecionamento. Todo objeto que pertence a uma coleção está nessa condição por decisão de alguém ou de algum grupo, seja por raridade, acontecimento histórico, memória, autenticidade, religiosidade. Por coleção consideramos "um conjunto de artefatos que um indivíduo ou estabelecimento, se responsabilizou por reunir, classificar, selecionar e conservar em um contexto seguro" (DESVALLÉES e MAIRESSE, 2013, p. 32). De acordo com os autores, no Brasil e em Portugal encontramos outros correlatos, tais como "acervo". Neste sentido, acervo está colado ao conceito de coleção.

É possível pensar que toda coletividade humana dedica-se a alguma atividade de colecionamento, embora nem todos façam com os mesmos propósitos e valores. Um dos espaços institucionais que no contexto globalizado das modernas sociedades ocidentais abrigam e exibem as coleções são os museus (GONÇALVES, 2007) e os acervos. Como instituições culturais, acabam assumindo funções e significados distintos, conforme os contextos sociais e culturais. O Conselho Internacional de Museus (ICOM) definiu em 2007 o museu como uma instituição "a serviço da sociedade e do seu desenvolvimento, aberta ao público, que adquire, conserva, estuda, expõe e transmite o patrimônio material e imaterial da humanidade e do seu meio, com fins de estudo, educação e deleite" (ICOM, 2014).

Nota-se que na fala de Savaris não é clara a ideia de acervo, já que "nós não tínhamos compromisso com o rigor, com esse rigor histórico de museu, não era esse o nosso foco" (Manoelito Carlos Savaris, entrevista, maio de 2015). O acervo não é um espaço institucionalizado como museu. Suas atividades não contam com exposições e ambiente destinados à visitação para o público. Além do mais, as formas de registro e documentação não são padronizadas como também não é protegido e reconhecido pelo 
Instituto do Patrimônio Histórico e Artístico Nacional (IPHAN). Mas, suas práticas tangenciam este universo, já que o olhar para o espaço está atrelado ao guardar, conservar e estudar artefatos.

O importante é perceber que embora a proposta do Acervo de Indumentária do MTG transpasse os processos convencionais de categorização e conceituação, ela desloca e desvia o olhar das práticas tradicionais de conceituação dos museus. Uma prática não normatizada em museus, mas que é comum no acervo é o empréstimo de roupas. Pochmann diz que "não serve só para o Desfile Temático, tem sido emprestado para outras cidades, para outros eventos também" (Ana Marta Vasconcelos Pochmann, entrevista, dezembro de 2014).

Além do mais, todas as peças que dão forma ao acervo foram produzidas ou doadas para o Desfile Temático. De acordo com Savaris "muita coisa é feita em casa, muita coisa o próprio pessoal do CTG faz e em pequenas quantidades" (Manoelito Carlos Savaris, entrevista, maio de 2015). Ele conta que desde 2009 os CTGs passaram a confeccionar suas próprias roupas para o Desfile Temático e, em seguida, eram doadas para o acervo.

Por conta desses atravessamentos e diferentes práticas, optamos por estudar com um conceito amplo que pudesse dar suporte para trabalharmos com o objeto de pesquisa: o de patrimônio. Ao encontro de Arpin (2000 apud DESVALLÉES e MAIRESSE, 2013) entendemos patrimônio como "todo objeto ou conjunto material, reconhecido e apropriado coletivamente por seu valor de testemunho e de memória histórica e que deve ser protegido, conservado e valorizado". O patrimônio é aqui compreendido como um bem público cuja preservação é feita por coletividades.

Ao pensar no ato de tornar um bem como valor de patrimônio, isto é, processo cultural daquilo que está ligado com a identidade e a memória coletiva, passamos a refletir a respeito da patrimonialização. Lima (2012, p. 34) configura o termo patrimonialização como sendo "um ato que incorpora à dimensão social o discurso da necessidade do estatuto da preservação". Importa, então, compreender e entender de que maneira se dá o processo de patrimonialização do Acervo de Indumentária do MTG. Nas narrativas dos(as) interlocutores(as) e na matéria encontramos potencialidades de reconstruir esses discursos de identidade gaúcha. 
Visto isso, é importante esclarecer qual a utilização e a função deste acervo para cada interlocutor(a). Ao perguntarmos para cada um(a) como eles(as) definem o Acervo de Indumentária, foi possível perceber que as explicações partiram de suas experiências.

O objetivo do acervo é para as pessoas desfilarem, e aqui tu encontra (...) vamos dizer (...) $80 \%$ do material. Então tu não tem que mandar fazer, tu não tem a despesa extra, vai sair tudo certinho, tudo direitinho. Tu não vai sair com uma calça de uma cor, um casaco de outra, todo bagunçado na avenida. Então eu acho que esse é o objetivo do acervo. É a gente encontrar o material que está aqui dentro né. (Ana Beatriz Souza Debom, entrevista, maio de 2015).

O acervo serve (...) para o próprio estudo da história do Rio Grande do Sul, porque aqui o pessoal tentou fazer isso, né Ana? (Ana Marta Vasconcelos Pochmann, entrevista, maio de 2015).

O importante do acervo é a (...) que tu mantém essa cultura e que as pessoas possam ter aonde (...) por exemplo, tu está pesquisando e alguém quer entrar no movimento (...) de que forma? Se ele quer ter o conhecimento nós temos todo esse aparato ali para auxiliar nesse processo (...) desde os costumes do passado até hoje. Isso é o maior, eu acredito que isso seja uma contribuição muito grande que o movimento dá para aquelas pessoas que não têm o entendimento ainda. (Gustavo Bierhals, entrevista, maio de 2015).

O acervo (...) para mim? É o retrato da teatralização dos Festejos Farroupilhas. Ele é de alguma forma o que sobra do temário de cada ano. (Manoelito Carlos Savaris, entrevista, maio de 2015).

Na verdade (...) é, nós temos um acervo histórico-cultural muito significativo. Cada peça tem a sua história, sua origem, não de quem usou no desfile (...) não alguém que usou em alguma atividade, mas sim a representatividade da origem, exatamente da formação do povo gaúcho. É com aquelas roupas que nós temos a apresentação do Rio Grande do Sul, da formação, da raça formadora. Eu acho que é isso, a riqueza que ele tem no que ele traduz, na sua expressão. Ele tem um lugar de representatividade. (Odila Paese Savaris, entrevista, dezembro de 2014).

Percebemos que os sujeitos, cada com suas experiências, procuram explicar qual é o sentido do acervo, do MTG, do tradicionalismo, do ser gaúcho. Fica evidente que o ser gaúcho é plural e com múltiplos interesses. Para Debom é um espaço que permite que os participantes do movimento se vistam adequadamente para o Desfile. Para Pochmann é uma maneira de estudar, via materialidade dos trajes, as histórias do estado. Bierhals enfatiza que o acervo é como um suporte para entender o movimento. Savaris o relaciona com o Desfile, como uma memória do que o Desfile Temático procura retratar: a história e os costumes do estado. E, para Odila, as roupas constituem e reconstroem as histórias de um passado no presente. 
Logo, com a ajuda da indumentária é possível entender como as pessoas enxergam o mundo, compreendendo, assim, como as práticas sociais e culturais relacionam-se com o vestuário. Esses artefatos contribuem com a história social e as memórias individuais e coletivas de uma sociedade. Diferente de encarar a vestimenta apenas como uma forma de representação ou um signo semiótico, o vestuário desempenha um papel atuante na constituição particular do eu e são diferentes de acordo com a experiência espaço-tempo dos sujeitos.

$\mathrm{Na}$ tentativa de observar essa pluralidade de sentidos, nos apoiamos em MartínBarbero (2004) que utiliza da cartografia como metáfora para justificar sua forma de pesquisar e escrever. De acordo com o autor, as cartografias e os mapas estão relacionados com a distorção de algo e nessas representações há filtragem da informação, reduzindo e simplificando os elementos. O mapa omite, deforma, apaga, suprime.

O autor propõe que nos desprendamos dessas representações e ainda nos indaga: "mas quem disse que a cartografia só pode representar fronteiras e não construir imagens das relações e dos entrelaçamentos, dos caminhos em fuga e dos labirintos?" (MARTÍN-BARBERO, 2004, p. 12). Esse questionamento nos permite refletir sobre outras formas de olhar algo que estamos investigando. Também nos chama a atenção para pensar em outras formas de escrita e produção acadêmica. Nesta pesquisa, nos deparamos com diversos relatos e perguntas que descentram o nosso olhar como pesquisadores(as). O protagonista não é mais um, e sim, tantos outros sujeitos. E é essa multiplicidade de questões e experiências que se procurou ao reconstruir fragmentos do processo de patrimonialização do Acervo de Indumentária do MTG.

\section{Catalogando memórias: processos de registro e organização}

Quando queremos proteger uma coisa ou um conjunto de coisas buscamos, de algum modo, preservar. Na museologia, a preservação "engloba todas as operações envolvidas quando um objeto entra no museu, isto é, todas as operações de aquisição, entrada em inventário, catalogação, acondicionamento, conservação e, se necessário, restauração" (DESVALLÉES e MAIRESSE, 2013, p. 80). Neste sentido, ela é um requisito fundamental, dado que estrutura e organiza as coleções que tecem o museu. 
Além de não ser um museu reconhecido pelo Instituto Brasileiro de Museus IBRAM, o Acervo de Indumentária do MTG não é um projeto que compõe os programas do Plano Museológico do IPHAN e não utiliza ferramentas desta ou de outra instituição reconhecida no ambiente museológico para organizar e inventariar seus artefatos. Mas, procura, com suas especificidades, guardar e preservar coisas.

Enquanto o acervo permaneceu sob os cuidados de Basso, ele admite que "não tinha uma sala tratada para isso, era uma questão de bom senso" (Josemar Basso, entrevista, maio de 2015). Savaris pronuncia que a organização e seu planejamento foram "por conta. Sem dúvida. Não teve nenhum programa e não visitamos nenhum acervo do tipo. Nem conhecemos um acervo parecido com esse" (Manoelito Carlos Savaris, entrevista, dezembro de 2014). A falta de profissionais necessários para este tipo de trabalho e de pesquisa fez com que o movimento agisse baseado em suas intuições. Assim, durante estes doze anos de existência, as mudanças ocorridas na organização, catalogação e registro dos artefatos no acervo foram realizadas por meio das experiências dos indivíduos que agiram no local.

Basso foi o precursor da prática de preservação do acervo. Ele conta que nos primeiros anos a sala reservada para o acervo ficava na Office Marketing, empresa de que ele era sócio. Pelo fato da haver uma sala ampla e muito maior que os espaços que a Fundação Cultural Gaúcha tinha, as indumentárias ficaram acondicionadas lá por cerca de três anos. Depois desse período o acervo passou a ser construído em uma das salas da Fundação e em 2014 foi transferido para um Centro Cultural na Zona Sul da cidade de Porto Alegre.

Quanto ao princípio que Basso utilizou para organizá-lo foi a facilidade de localizar e identificar as indumentárias. Como não era um participante tradicionalista do MTG e, sim, colaborador, ele não sabia reconhecer claramente os tipos de trajes contidos naquele espaço. Deste modo, era preciso outra estratégia.

\footnotetext{
Eu tinha uma quantidade de roupa que eu tinha uma preocupação em que ela não se perdesse, em primeiro lugar, e em segundo lugar para ter certeza quando fosse guardado o que era (...) pra não ter que procurar (...) porque eu não tinha conhecimento técnico disso. Então o que é que eu fiz (...) com as fotos que estavam em cada coisa, a gente chegava, olhava, via e de acordo com aquela foto que o pessoal tinha a gente foi fazendo o catálogo disso aí tudo, entende? (Josemar Basso, entrevista, maio de 2015).
} 
Seu principal cuidado era com a preservação das peças, no sentido de deixá-las inteiras. Ao falar que não queria perdê-las, Basso afirma que existia uma preocupação de tornar esses artefatos testemunhos de sua época e do seu trabalho, além de ser uma forma de preservar aquilo que o movimento entende por tradição e identidade gaúcha. A noção de que práticas culturais de preservação têm o propósito de representar categorias sociais e culturais perpassa o argumento de Gonçalves (2002) ao afirmar que "práticas de colecionamento respondem ao desafio de salvar esses objetos do desaparecimento" (GONÇALVES, 2002, p. 22). O autor é categórico ao pronunciar que as práticas de colecionamento são entendidas como um esforço de defender a continuidade e a integridade do que define a identidade e memória de uma nação, estado ou instituição.

Para iniciar a tarefa do colecionamento, Basso se apropriou de imagens para facilitar a identificação do que continham os cabides com sacos plásticos. Ao percorrer pelo acervo nos anos de 2014 e 2015, avistamos algumas dessas imagens a que o interlocutor faz menção. Atualmente, muitas delas não correspondem às indumentárias contidas nas capas, o que consiste em uma prática de organização obsoleta. Pochmann refere-se a este modo de fazer como algo que caiu em desuso: "e nos cabides também, está tudo (...) deveria ter né, e tinha etiquetinhas. Conforme foi usando, as etiquetas se perderam. Não tem mais a descrição. Tinha tipo isso aqui ó (mostra uma etiqueta) escrito a peça que ia em cada saco" (Ana Marta Vasconcelos Pochmann, entrevista, maio de 2015). A Figura 5 declara estas marcas e formas de catalogar as peças.

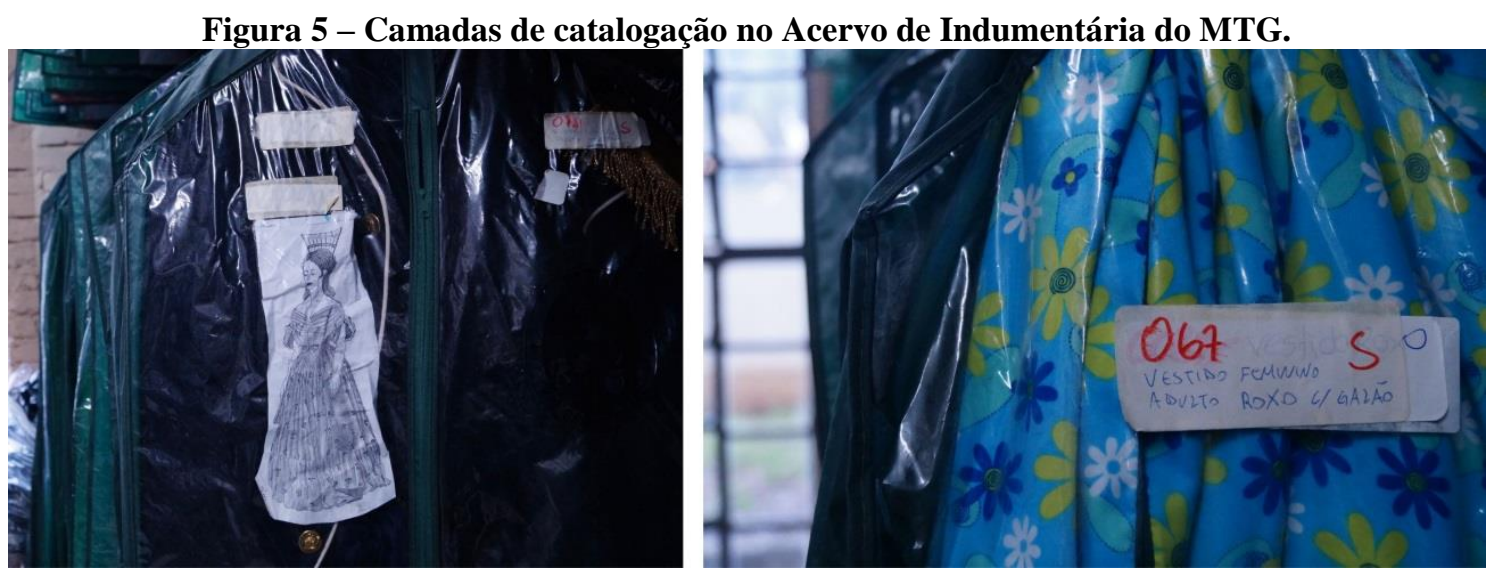

Fonte: A autora (08.07.2015).

Os trabalhos realizados por Basso e Pochmann, entre outros que participaram desse processo, estão materializados nos cabides com sacos plásticos. São rastros 
marcados no material. As sobreposições de algumas etiquetas, o rasgo de outras e a descontinuidade das figuras como reconhecimento do conteúdo que havia nos sacos evidenciam formas de pensar o espaço, os registros e a catalogação das indumentárias.

Outra preocupação de Basso era manter as coisas mais utilizadas pelo Movimento próximas aos olhos: “eu não posso ver o evento somente no ano de 2015. Eu tenho que pensar que eu tenho um setor, que eu vou fazer evento todo ano e que eu vou precisar. Necessariamente não vou usar isso todos os anos, mas tem um ano que posso usar" (Josemar Basso, entrevista, maio de 2015). Além de separar as peças em sacos plásticos e cabides, seu método de organização do acervo era construído pensando na quantidade de usos dos objetos.

Enquanto o acervo esteve sob sua responsabilidade, Basso conta que o empréstimo de roupas era realizado somente quando "tinha certeza que ia me devolver lavadinho, bonitinho, tudo mais, entende?" (Josemar Basso, entrevista, maio de 2015). Ou seja, o empréstimo se dava para as pessoas em que Basso confiava. Para mostrar que seu procedimento teve êxito, ele afirma que "o que foi, voltou". Desde o período em que Pochmann assumiu a coordenação do acervo, o empréstimo das roupas é realizado através de um protocolo. $\mathrm{O}$ (a) interessado(a) deve preencher um formulário solicitando a peça desejada. Segundo Pochmann, o controle é feito via protocolo, seguindo sempre o mesmo modelo.

As formas pelas quais Basso e Pochmann procuraram organizar e expor as indumentárias são uma leitura possível. Nas palavras de Lourenço "memória e patrimônio sempre abrangeram conflitos, fusões, articulações e perdas" (LOURENÇO, 2015, p. 25). Objetos classificados, inventariados e sistematizados representam escolhas e tentam comunicar narrativas fundadas no conhecimento de cada sujeito que participou do evento.

Basso com a equipe da Office Marketing organizou um inventário. Segundo Basso, neste documento constavam a quantidade e as categorias de indumentárias que constituíam o Acervo de Indumentária do MTG. De acordo com ele, quando o acervo foi transferido da Office Marketing para a sede da Fundação, os desenhos feitos por Acri e este inventário foram encaminhados com as indumentárias. Quando questionamos Pochmann acerca deste documento, ela respondeu que "ficou lá na Fundação e não veio para mim. Nem sei se vou achar mais agora, porque ficou nas 
gavetas da mesa e eles tiraram tudo" (Ana Marta Vasconcelos Pochmann, entrevista, dezembro de 2014). Em seguida, ela explica que esse documento, elaborado pela equipe de Basso, não foi utilizado quando o acervo foi transferido para a Fundação, pois "nós tentamos, eu e a Ana, tentamos fazer (...) nós até fizemos a relação de todas as roupas (...) acho que foi no $1^{\circ}$ ou no $2^{\circ}$ ano que a gente pegou, a gente fez a relação todinha" (Ana Marta Vasconcelos Pochmann, entrevista, dezembro de 2014).

Essas alterações de espaços acabaram ocasionando perdas e variações quanto aos modos de registrar o patrimônio contido no acervo. Pochmann conta que com a ajuda de Debom reconstruiu o inventário sem o auxílio de ferramentas computacionais, e sim, com lápis e papel. Novamente, quando o acervo foi deslocado para o Centro Cultural Zona Sul em 2014, este documento foi perdido, pois havia apenas o manuscrito original. A interlocutora diz que não há um inventário atualizado das peças. Ao explorar o Acervo de Indumentária no Centro Cultural Zona Sul, foram encontradas algumas cópias do inventário que pertence ao período de Basso, o que torna possível pensar que além das formas de catalogação, outras memórias do processo de patrimonialização ainda permanecem materializadas, porém esquecidas.

O primeiro arquivo encontrado foi o intitulado "Patrimônio - Indumentárias e Bandeiras". No caso da palavra patrimônio contida no título do documento, considerouse que ela se refere, fundamentalmente, às indumentárias e bandeiras como um valor simbólico de uma identidade coletiva (FONSECA, 2005). A classificação foi realizada de acordo com o nome da indumentária/bandeira seguida de uma numeração que sugere ser a quantidade de peças que havia por indumentária/bandeira.

O próximo documento localizado foi o chamado "Cabides", o que permite concluir que o inventário acima é referente às peças organizadas em sacos plásticos. Este documento possui uma tabela composta por duas colunas: uma com o número e outra com a descrição da indumentária. Ao visualizarmos estes números presumimos que eles faziam sentido com a numeração que havia encontrado nos cabides com capas de plástico, mas não havia semelhança. Basso conta que na época em que eles realizaram este inventário existia tal relação para o controle e também para a facilidade de acesso aos trajes. 
Figura 6 - Inventários realizados no período em que o acervo esteve sob responsabilidade de Josemar Basso.
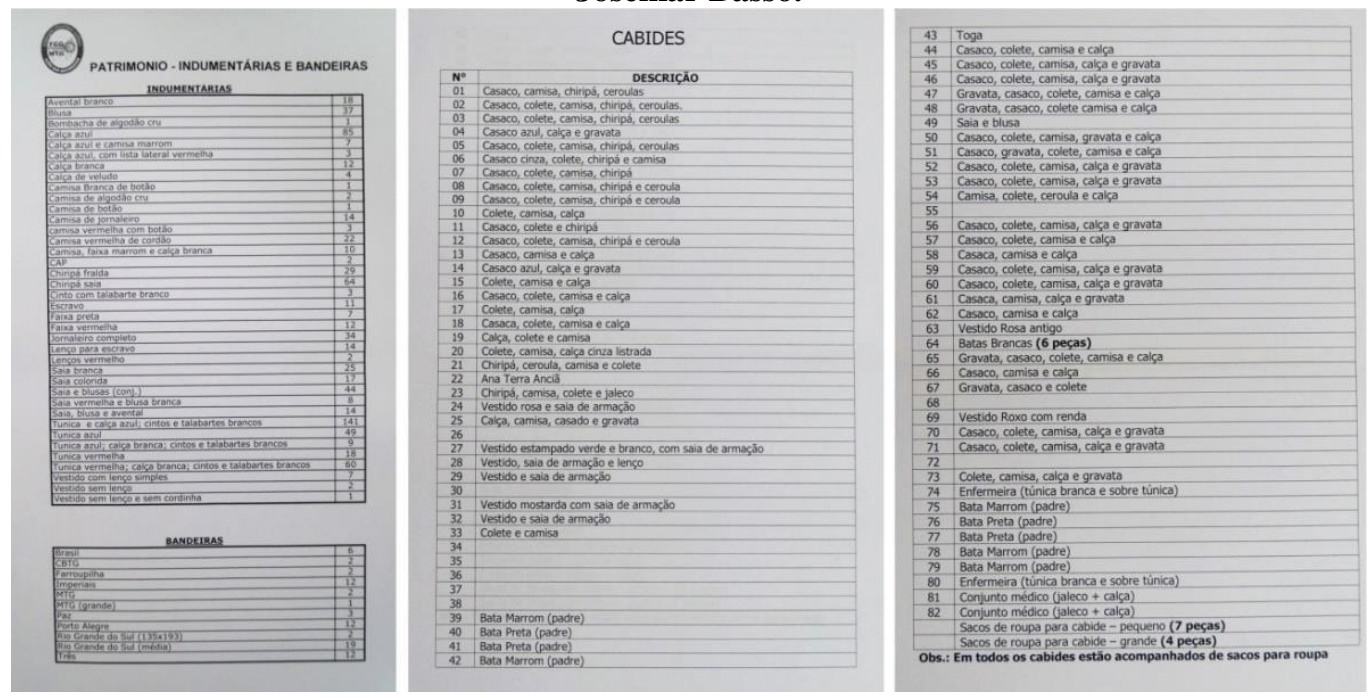

Fonte: A autora (09.07.2015).

Mesmo que o controle atualmente não seja feito com base neste inventário, Pochmann e Debom iniciaram suas atividades utilizando estes documentos como referência: "nós nos guiamos justamente pela relação do Josemar" (Ana Marta Vasconcelos Pochmann, entrevista, maio de 2015). Assim, no momento em que Pochmann e Debom assumiram a organização do acervo na Fundação, Savaris comprou caixas plásticas para guardar as indumentárias que antes eram mantidas em sacos plásticos nas prateleiras. Para saber o que havia em cada caixa, Pochmann e Debom assumiram a estratégia de colar etiquetas escritas à mão na lateral de cada uma delas.

Mas o curioso foi que enquanto Pochmann e Debom mostravam as caixas e as etiquetas, notamos a presença de números colados (Figura 7), provavelmente feitos com o auxílio de uma ferramenta computacional. Debom responde que "é, nós tínhamos assim ó: número 1, 2, 3, 4, era tudo numerado pra gente saber. Esses não eram nossos números (imagem atual do acervo). Os nossos eram à mão, nós fazíamos um papelzinho e colava né” (Ana Beatriz Souza Debom, entrevista, maio de 2015). 
Figura 7 - Formas de registro das indumentárias em caixas plásticas.
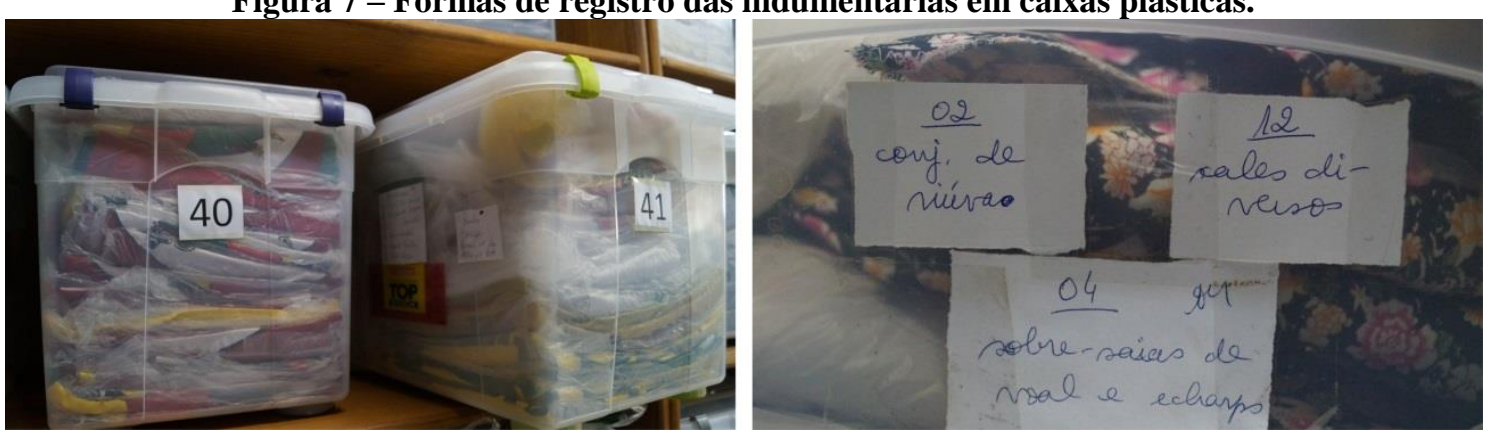

Fonte: A autora (15.07.2015).

As etiquetas coladas pelas interlocutoras eram localizadas na vista lateral da caixa, pois enquanto estavam na Fundação elas eram colocadas de tal forma que essa vista era a visível. Hoje, a disposição das caixas permite que a parte frontal seja visível e a lateral não, dificultando a visibilidade das etiquetas e do que há em seu interior.

Em conformidade com os relatos dos(as) interlocutores(as), houve basicamente duas formas de arranjar os espaços nos quais o acervo esteve presente, a saber, os cabides com capas de plástico e os sacos plásticos, ora organizados em prateleiras, ora em caixas plásticas. A diferença era com relação ao tipo de traje, material e acabamentos utilizados nas peças. As indumentárias com muitos aviamentos e cujos tecidos não permitiam dobrar eram armazenadas em cabides com capas de plástico. Já as indumentárias e outros artefatos sem muitos aviamentos e que foram confeccionadas com tecidos que permitem a dobra foram posicionados em caixas plásticas. A maioria das peças expostas em cabides são vestidos e fraques. O tamanho e a quantidade de detalhes que eles têm, por exemplo, impossibilita a colocação nas caixas plásticas.

Desde o início de 2014 o acervo está estruturado no Centro Cultural Zona Sul. A mudança de local aconteceu devido ao tamanho da sala que foi cedida na Fundação e pelos estragos e perdas que a umidade vinha gerando. A sala hoje ocupada é consideravelmente maior. Além disso, sua luminosidade, a janela que permite ventilação e entrada de ar além do alto pé direito oferecem melhores condições se comparados com a anterior. Isso porque na sala da Fundação não havia janela, o pé direito não alcançava 2 metros e era localizada no subsolo da infraestrutura. 
Figura 8 - Organização das caixas plásticas em prateleiras no Centro Cultura Zona Sul.

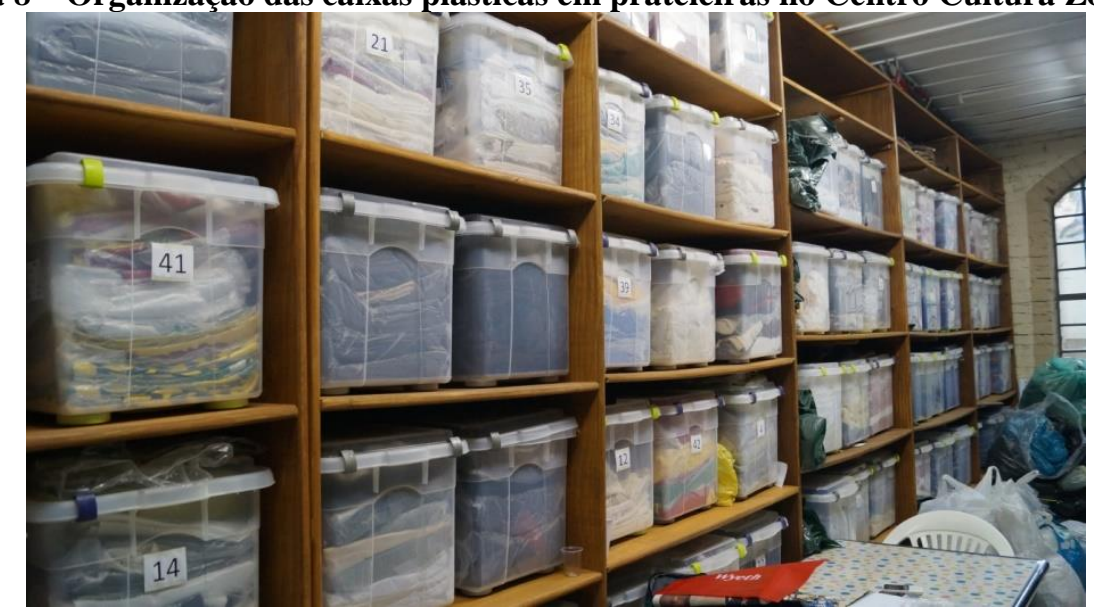

Fonte: A autora (08.07.2015).

Figura 9 - Indumentárias organizadas em cabides com sacos plásticos no Centro Cultural Zona Sul.

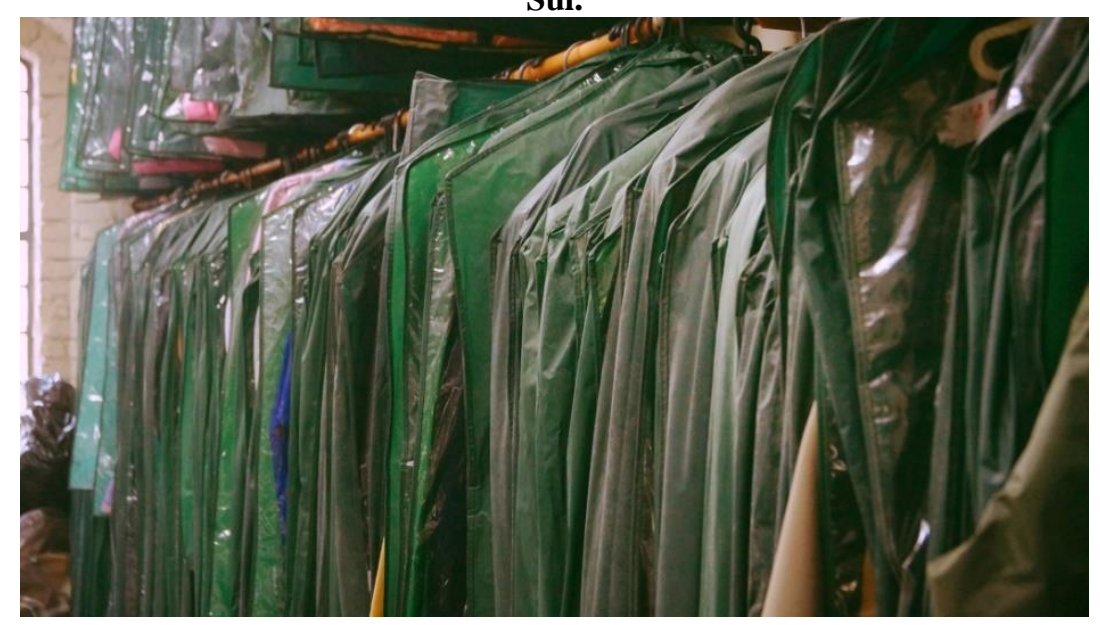

Fonte: A autora (08.07.2015).

Portanto, as formas de colecionar aqui expostas não são práticas suportadas pelas regras e condições tradicionais de patrimonialização, mas uma estratégia discursiva do MTG para legitimar e mostrar a importância que as roupas têm para a entidade. Os sujeitos envolvidos nesse processo procuraram catalogar memórias e registrar histórias sobre o movimento a partir das indumentárias. As coisas têm o poder de guardar sinais de trabalho e de quem os fez. E foi com apoio nas narrativas e nas marcas materiais que descrevemos e reconstruímos os modos de documentar esse patrimônio. 


\section{Considerações finais}

Este artigo teve como objetivo reconstruir uma narrativa sobre o processo de construção e patrimonialização do Acervo de Indumentária, idealizado pela Fundação Cultural Gaúcha do Movimento Tradicionalista Gaúcho (MTG) de Porto Alegre. A partir dos relatos dos(as) interlocutores(as), somados às fontes escritas, tais como documentos, registros fotográficos e diários de campo, foi possível registrar fragmentos do processo de patrimonialização do acervo.

Nesse sentido, nos interessou considerar o protagonismo dos(as) interlocutores(as) no processo de constituição do acervo, bem como suas experiências e aprendizados com relação aos artefatos dispostos no local. Ao entrevistar outros sujeitos que participaram deste processo, outras falas e experiências surgiram.

Os artefatos encontrados no Acervo de Indumentária nos contam histórias sobre como foram feitos, quais materiais e tecnologias foram utilizados, bem como de que contexto cultural-histórico foram construídos. Também nos contam histórias das pessoas que projetaram, fabricaram, consumiram, colecionaram e participaram da ideia do que é ser gaúcho dentro do circuito que envolve o MTG. Ao tornarem-se peças constituintes de espaços de patrimônio, as indumentárias passam a ser testemunhas de sua época, oferecendo oportunidades de reflexão e continuidade às nossas histórias.

Entendemos, assim como Benarush que "a catalogação e a documentação das peças são ações cruciais na gestão do acervo" (BENARUSH, 2015, p. 107). Entretanto, a catalogação das peças deste objeto de pesquisa encontra dificuldades. Por ser uma ação que procura guardar e documentar seus valores históricos e culturais poderia existir uma ficha catalográfica que qualifica as informações dos artefatos, uma reserva técnica onde os artefatos são armazenados e o restauro e lavagem das peças poderiam ser realizados por um(a) especialista. Mas, o processo é incipiente e tais questões podem ser levadas ao movimento como futuras contribuições.

Observando as práticas sociais e culturais no universo do MTG e do acervo ao longo da pesquisa exploratória, nota-se a importância da indumentária para a constituição da figura do gaúcho. O patrimônio, reconhecido pelo movimento como acervo, tem incorporado objetos importantes seu sistema cultural, em que os trajes ali contidos são agenciadores de sentidos. Desta forma, compreendemos que os desejos e 
as vontades de contar a visão do movimento sobre o tradicionalismo e a cultura gaúcha são investidos materialmente.

Artigo recebido em Dezembro de 2015. Aprovado em Maio de 2016

DOI:http://dx.doi.org/105965/1982615×09182016144

\section{Referências}

BENARUSH, M. K. Moda é patrimônio. In: CAMARGO, P. de O.; RIBEIRO, P. E. V. L.; WASHINGTON, F. (Org.). Moda e/é patrimônio. Rio de Janeiro: CCD, 2012. p. 85-95.

BENARUSH, M. K. Por uma museologia do vestuário: patrimônio, memória, cultura. In: MERLO, M. (Org). Memórias e museus. São Paulo: Estação das Letras e Cores, 2015. p. 99-111.

BENJAMIN, W. O narrador: considerações sobre a obra de Nikolai Leskov. In: BENJAMIN, W. Magia e técnica, arte e política: ensaios sobre literatura e história da cultura. São Paulo: Brasiliense, 1994, p. 197-221 (Escrito em 1936 sob o título Der Erzähler: Betrachtungen zum Werk Nikolai Lesskows).

BOSI, E. Memória e sociedade: lembranças de velhos. São Paulo: Cia. Das Letras, 1994.

CORRÊA, R. de O. Narrativas sobre o processo de modernizar-se: uma investigação sobre a economia política e simbólica do artesanato recente em Florianópolis, Santa Catarina, BR. Florianópolis, 305 p. Tese (Doutorado Ciências Humanas) - Programa do Doutorado Interdisciplinar em Ciências Humanas, Universidade Federal de Santa Catarina, Florianópolis, 2008.

CORRÊA, R. de O.; RIAL, C. S. M.; QUELUZ, G. L. A finalidade é a gente trabalhar aqui mesmo, no ateliê (...) Processos de refuncionalização dos ateliês de artesãos (ãs) no circuito econômico e cultural em Florianópolis, SC. In: RIAL, C.; SILVA, S. R.; SOUZA, A. M. (org.).Consumo e cultura material: perspectivas etnográficas. Florianópolis: Ed. Da UFSC, 2012. p. 49-74.

DESVALlÉES, A.; MAIRESSE, F. Conceitos-chave de museologia. Tradução de: SOARES, B. B.; CURY, X. M. São Paulo: Comitê Brasileiro do Conselho Internacional de Museus: Pinacoteca do Estado de São Paulo: Secretaria de Estado da Cultura, 2013. 
EMÍDIO, L. de F. B.; AYRES, M. A. M.; Nunes, V. A. V. Mão de obra no cenário competitivo da pequena empresa de confecção do vestuário: um estudo de caso. In: Colóquio de Moda - Edição Internacional, 10., 2014, Caxias do Sul. Anais... Caxias do Sul, 2014.

FONSECA, M. C. L. O patrimônio em processo: trajetória da política federal de preservação no Brasil. Rio de Janeiro: Ed. UFRJ: MinC: Iphan, 2005.

GIL, A. C. Como elaborar projetos de pesquisa. $4^{\text {a }}$ ed. São Paulo: Atlas, 2002.

GONÇALVES, J. R. S. A retórica da perda: os discursos do patrimônio cultural no Brasil. Rio de Janeiro: Editora UFRJ; Iphan, 2002.

GONÇALVES, J. R. S. Antropologia dos objetos: coleções, museus e patrimônios. Rio de Janeiro: Editora Garamond, 2007.

HALBWACHS, M. A Memória Coletiva. São Paulo: Revista dos Tribunais Ltda, 1990.

ICOM. Museum Definition. Disponível em: <http://icom.museum/the-vision/museumdefinition/>. Acesso em: 20 nov. 2014.

LIMA, D. F. C. Museologia-Museu e Patrimônio, Patrimonialização e Musealização: ambiência de comunhão. Boletim do Museu Paraense Emílio Goeldi. Ciências Humanas, v. 7, n. 1, p. 31-50, jan.-abr. 2012.

LOURENÇO, M. C. F. Museus e desafios na atualidade. In: MERLO, M. (org.). Memórias e museus. São Paulo: Estação das Letras e Cores, 2015. p. 19-35.

MARTÍN-BARBERO, J. Aventuras de um cartógrafo mestiço. In: MARTÍNBARBERO, J. Ofício de Cartógrafo. Travessias latino-americanas da comunicação na cultura. São Paulo: Edições Loyola, 2004. p. 9-42.

MILLER, D. Trecos, troços e coisas: estudos antropológicos sobre cultura material. São Paulo: Zahar, 2013.

MOVIMENTO TRADICIONALISTA GAÚCHO - MTG. O que é MTG. Disponível em: <http://www.mtg.org.br/pag_oqueemtg.php>. Acesso em: 02 set. 2014.

NORA, P. Entre memória e história: a problemática dos lugares. Tradução de: KHOURY, Y. A. Projeto História, São Paulo, v.10, p. 7-28, 1993.

POLLAK, M. Memória e identidade social. In: Revista Estudos Históricos, v. 5, n ${ }^{\circ} 10$, p. 200-212, Rio de Janeiro, 1992.

SANTOS, M. R. dos. Design e cultura: os artefatos como mediadores de valores e práticas sociais. In: QUELUZ, Marilda L. (Org.). Design \& Cultura. Curitiba: Editora Sol, 2005. 
TESSARI, V. F. dos S. Fazer é pensar, pensar é fazer: O trabalho e os artefatos na Fábrica Zeferino, Novo Hamburgo, RS. 2014. 191p. Dissertação (Mestrado em Tecnologia) - Programa de Pós Graduação em Tecnologia, Universidade Tecnológica Federal do Paraná, Curitiba. 2014.

\section{Entrevistas concedidas}

BASSO, J. Entrevista concedida em maio de 2015. Porto Alegre (RS).

BIERHALS, G. Entrevista concedida em maio de 2015. Porto Alegre (RS).

DEBOM, A. B. S. Entrevista concedida em maio de 2015. Porto Alegre (RS).

POCHMANN, A. M. V. Entrevista concedida em dezembro de 2014. Porto Alegre (RS).

POCHMANN, A. M. V. Entrevista em maio de 2015. Porto Alegre (RS).

SAVARIS, M. C. Entrevista concedida em dezembro de 2014. Porto Alegre (RS).

SAVARIS, M. C. Entrevista concedida em maio de 2015. Porto Alegre (RS).

SAVARIS, O. P. Entrevista concedida em dezembro de 2014. Porto Alegre (RS). 